\title{
Avaliação do efeito de cepas probióticas em biofilme de $S$. aureus sobre discos de titânio com superfície tratada
}

\author{
Assessment of probiotic bacterial strains effect on $S$. aureus biofilm on \\ titanium discs with treated surfaces
}

\author{
Mariana Cavalcante Costa MORAES ${ }^{*}$ (D), Pedro Jorge Cavalcante COSTA ${ }^{a}$ (D), \\ Aguinaldo Silva Garcez SEGUNDO ${ }^{\text {b }}$ (D), Daiane Cristina PERUZZO ${ }^{\text {b }}$ (1) \\ a UNIT - Centro Universitário Tiradentes, Maceió, AL, Brasil \\ b São Leopoldo Mandic, Faculdade de Odontologia e Centro de Pesquisas Odontológicas, Campinas, SP, Brasil
}

\author{
Como citar: Moraes MCC, Costa PJC, Segundo ASG, Peruzzo DC. Avaliação do efeito de cepas probióticas em biofilme de \\ S. aureus sobre discos de titânio com superfície tratada. Rev Odontol UNESP. 2019;48:e20190096. \\ https://doi.org/10.1590/1807-2577.09619
}

\begin{abstract}
Resumo
Introdução: As doenças peri-implantares apresentam como um dos principais fatores etiológicos o biofilme bacteriano, geralmente formado por uma microbiota semelhante à das doenças periodontais. Seu tratamento está centrado na descontaminação da superfície do implante e na remoção mecânica do biofilme, podendo ainda estar associado à administração de agentes antimicrobianos. Nesse sentido, tem sido cogitada a utilização de probióticos, que são microrganismos benéficos à saúde e que podem ter grande importância na cavidade oral, como coadjuvante no tratamento das peri-implantites. Objetivo: Avaliar o efeito das cepas probióticas de Lactobacillus brevis e Bifidobacterium bifidum no crescimento do biofilme monoespécie de Staphylococcus aureus. Material e método: Discos de titânio padronizados e com superfície tratada foram submersos em meio contendo caldo BHI e Staphylococcus aureus durante sete dias. Após esse período, o caldo foi retirado, os discos foram lavados e, então, introduzidos em um novo caldo BHI contendo as suspensões probióticas, sendo assim comparados a um grupo controle, sem probióticos. As amostras foram incubadas por $24 \mathrm{~h}$ e então foram realizadas as diluições e a contagem das UFC (unidades formadoras de colônia) para Staphylococcus aureus. Resultado: Após análise estatística dos dados, observou-se que a adição de ambos os probióticos resultaram em redução significativa $(\mathrm{p}<0,05)$ de UFC, quando comparados ao controle. Conclusão: Conclui-se que os probióticos analisados (Lactobacillus brevis e Bifidobacterium bifidum) reduziram consideravelmente o crescimento do patógeno Staphylococcus aureus. Além disso, a cepa de Lactobacillus brevis apresentou efeito inibidor superior ao da cepa Bifidobacterium bifidum para ser utilizada como controle do biofilme bacteriano de Staphylococcus aureus.
\end{abstract}

Descritores: Probióticos; peri-implantite; Bifidobacterium bifidum; Lactobacillus brevis.

\begin{abstract}
Introduction: One of the main etiological factors for peri-implant diseases is the bacterial biofilm, which usually features a similar microbiota to periodontal diseases. Its treatment focus on the decontamination of the implant surface and on the mechanical removal of biofilm, and it may also be associated to the administration of antimicrobial agents. Thus, the use of probiotics has been considered, since they feature beneficial microorganisms to health and may be of great importance for the oral cavity as an adjunct for the treatment of peri-implant diseases. Objective: The aim of this in vitro study was to assess the effect of probiotic strains of Lactobacillus brevis and Bifidobacterium bifidum on the growth of single-species biofilm of Staphylococcus aureus. Material and method: Standardized surface-treated titanium discs were submerged in a medium containing BHI broth and Staphylococcus aureus, for 7 days. After this period, the broth was removed, the discs were washed and, then, submerged in a new BHI broth containing probiotic suspensions and compared to a control group (with no probiotics). Samples were incubated for 24 hours and then the dilutions and CFU (colony-forming units) counting for Staphylococcus aureus were performed.
\end{abstract}


Result: Statistical analysis revealed that the addition of both probiotics resulted in a significant reduction $(\mathrm{p}<0,05)$ of $\mathrm{CFU}$, when compared to the control group. Conclusion: The assessed probiotics (Lactobacillus brevis and Bifidobacterium bifidum) considerably reduced Staphylococcus aureus growth. In addition, Lactobacillus brevis strain presented a superior inhibition effect than Bifidobacterium bifidum strain for Staphylococcus aureus bacterial biofilm control.

Descriptors: Probiotics; peri- implantitis; Bifidobacterium bifidum; Lactobacillus brevis.

\section{INTRODUÇÃO}

As doenças peri-implantares são infecções orais "contemporâneas", que surgiram como resultado da instalação rotineira de implantes dentários osseointegrados na prática clínica. São caracterizadas pela destruição inflamatória dos tecidos de suporte circunjacentes ao implante, decorrente da formação de biofilme bacteriano em sua superfície. A composição microbiana dos biofilmes associados a esta doença é mista, inespecífica e muito semelhante à da periodontite ${ }^{1}$.

A sequência de eventos imunopatológicos e a composição qualitativa das células imunes nas infecções peri-implantares são caracterizadas pela predominância de neutrófilos, macrófagos e células T e B. No entanto, em comparação com a periodontite, a peri-implantite apresenta um infiltrado inflamatório mais extenso e resposta imune inata, maior gravidade da destruição tecidual e uma taxa de progressão mais rápida ${ }^{2,3}$. Frequentemente, é precedida de mucosite periimplantar, ou seja, inflamação nos tecidos moles.

Implantes afetados por mucosite peri-implantar tendem a abrigar microbiota com níveis mais elevados de bactérias Gram-negativas, incluindo Fusobacterium spp. e baixas proporções de microrganismos Gram-positivos ${ }^{4}$. Já na transição para a peri-implantite, verifica-se o surgimento de espécies Gram-negativas, móveis e anaeróbias ${ }^{5,6}$. No entanto, a microbiota pode se diferenciar da doença periodontal pela presença de Staphylococcus aureus, Staphylococcus epidermidis, Enterobacter aerogenes, Enterobacter cloace, Escherichia coli, Helicobacter pylori, Peptostreptococcus micra e Pseudomonas spp ${ }^{5,7,8}$.

Como formas de tratamento dessas doenças, além da remoção do biofilme, o tratamento da medicina interna com administração local ou sistêmica de agentes antimicrobianos também é realizado com o objetivo de eliminar as bactérias ${ }^{9,10}$. Desse modo, como alternativa às drogas antibacterianas, os probióticos, incluindo o uso de microrganismos, como lactobacilos e bifidobactérias, têm sido investigados ${ }^{11}$. Esses agentes, que foram aprovados como alimentos para usos específicos, são considerados geralmente seguros e, frequentemente, são um componente de alimentos fermentados.

Probióticos são bactérias Gram-positivas acidófilas capazes de promover saúde ao hospedeiro ${ }^{12} \mathrm{e}$, quando administrados em quantidades adequadas, atuam prevenindo a adesão, multiplicação e integração de bactérias patogênicas no biofilme, além de inibir o crescimento de alguns patógenos através de substâncias, como o ácido lático ${ }^{9}$. 0 interesse da utilização desses microrganismos se deve a dois principais mecanismos de ação: um relacionado à colonização bacteriana e outro relacionado à modulação da resposta do hospedeiro.

No entanto, é verificado escassez literária em relação aos estudos metodologicamente delineados sobre o uso de bactérias probióticas como terapia coadjuvante no tratamento da periimplantite. Nesse sentido, o objetivo deste estudo foi avaliar a eficácia dos probióticos na redução da microbiota do biofilme bacteriano de Staphylococcus aureus sobre a superfície tratada de discos de titânio como complemento terapêutico no manejo das doenças peri-implantares. 


\section{MATERIAL E MÉTODO}

\section{Comitê de Ética}

O presente estudo foi dispensado de ser submetido à análise do Comitê de Ética em Pesquisa do Centro de pesquisa e pós-graduação da Faculdade São Leopoldo Mandic - Campinas-SP, por tratar-se exclusivamente de pesquisa laboratorial sem envolvimento de seres ou materiais humanos.

\section{Cepas de Microrganismos}

Foram utilizadas cepas padrão de Lactobacillus brevis e Bifidobacterium bifidum, e do microrganismo patogênico Staphylococcus aureus, fornecidas e mantidas em freezer a menos $80^{\circ} \mathrm{C}$ no Laboratório de Microbiologia da Faculdade São Leopoldo Mandic - unidade CampinasSP. Para a ativação desses microrganismos, as cepas de Lactobacillus brevis e Bifidobacterium bifidum foram cultivadas em ágar Man Rogosa e Sharpe (MRS), enquanto as cepas de S. aureus, em ágar soja tripticase (TSB, Oxoid). Todos foram inoculados da coleção de cultura e incubados por 48 horas a $37^{\circ} \mathrm{C}$ em $5 \%$ de teor de gás carbônico.

\section{Material}

Foram utilizados para análise discos de titânio padronizados grau IV, doados pela empresa SIN Implant System (São Paulo, Brasil), apresentando superfície tratada, diâmetro $6 \mathrm{~mm}$ e comprimento de $6 \mathrm{~mm}$.

Os discos de titânio foram divididos em três grupos distintos: LB: Lactobacillus brevis (LB); Bifidobacterium bifidum (BB), e Biofime de Staphylococcus aureus (BS) como controle positivo, sendo que cada grupo foi composto por 20 discos de titânio.

\section{Ensaio Experimental}

Inicialmente, os discos de titânio padronizados e doados pela empresa SIN Implant System (São Paulo, Brasil) foram submetidos à esterilização e, após a distribuição destes em três placas de microtitulação com 20 poços cada, foi adicionado $1 \mathrm{~mL}$ do caldo BHI (Brain heart infusion) cobrindo totalmente os discos e uma alíquota de $500 \mu \mathrm{L}$ da suspensão de Staphylococcus aureus contendo $10^{8}$ células/mL (1 Mc Farland) por um período de sete dias. A cada 24 horas, o caldo era trocado para possibilitar o crescimento do biofilme sobre a superfície dos discos. Para a formação do biofilme bacteriano, foi utilizada a metodologia descrita por Thein et al. ${ }^{13} \mathrm{com}$ algumas modificações, como a alteração do patógeno e o número reduzido de amostras.

Após este ciclo, o caldo foi retirado, os discos que já estavam com o biofilme na superfície foram lavados com solução salina estéril a $0,85 \%$ e então foram introduzidos $500 \mu \mathrm{L}$ de um novo caldo BHI e $500 \mu \mathrm{L}$ do caldo contendo as suspensões probióticas padronizadas de L. brevis e B. bifidum separadamente, com concentração de 1 Mc Farland cada. Os grupos foram incubados por 24 horas e comparados ao grupo controle (BS). Os discos foram novamente lavados com $5 \mathrm{~mL}$ de solução salina estéril para que as bactérias planctônicas fossem removidas e colocados em tubos estéreis (eppendorf 1,5 mL), sendo agitados em vórtex por 30 segundos para a remoção do biofilme. A solução bacteriana foi submetida a diluições seriadas, inoculadas em placas de petri com três alíquotas de $25 \mu \mathrm{L}$ de cada diluição com o meio BHI por 24 horas em estufa. Foi então 
realizada a contagem das unidades formadoras de colônia por $\mathrm{mL}$ (UFC/mL) para cada grupo de microrganismo.

\section{Análise e Estatística}

Após a realização da contagem de UFC, os dados inicialmente foram inseridos agrupados em planilha do Microsoft Office Excel. Posteriormente, as variáveis foram organizadas em tabela e descritas pelas medidas: média, mediana e desvio padrão (Tabela 1).

Os resultados foram submetidos ao teste one-way ANOVA e posteriormente ao post-Hoc de Tukey, comparando cada grupo. 0 programa utilizado foi o Bioestat 5.0. Para ambos os testes, foi possível verificar a homocedasticidade dos grupos, considerando o nível de significância de 5\% em todas as análises.

Tabela 1. Teste ANOVA para as comparações múltiplas e o teste $t$ de Tukey. BS: Biofilme de Sthaphylococcus aureus GFB como controle positivo; BB: Bifidobacterium bifidum; LB: Lactobacillus brevis

\begin{tabular}{cccccc}
\hline \multirow{2}{*}{ Discos de titânio } & \multicolumn{4}{c}{ Unidades Formadoras de Colônia (UFC) } & p-valor \\
\cline { 2 - 5 } & Média & Desvio padrão & Mediana & Letras & a \\
BS & $2,43 \times 10^{7}$ & $3,35 \times 10^{7}$ & $1,45 \times 10^{7}$ & $\mathrm{~b}$ & $<0.0001$ \\
BB & $5,21 \times 10^{6}$ & $2,33 \times 10^{6}$ & $4,47 \times 10^{6}$ & $\mathrm{c}$ \\
LB & $5,27 \times 10^{5}$ & $1,81 \times 10^{5}$ & $4,00 \times 10^{5}$ & \\
\hline
\end{tabular}

\section{RESULTADO}

Após análise, verificou-se que houve diferença significativa entre os grupos quando comparados em relação à quantidade de Unidades Formadoras de Colônia. Os grupos BS, BB e LB apresentaram as seguintes médias $\left(2,43 \times 10^{7} \mathrm{UFC} ; 5,21 \times 10^{6} \mathrm{UFC} ; 5,27 \times 10^{5} \mathrm{UFC}\right)$ e desviospadrões $\left(3,35 \times 10^{7} \mathrm{UFC} ; 2,33 \times 10^{6} \mathrm{UFC} ; 1,81 \times 10^{5} \mathrm{UFC}\right)$, respectivamente. Após a utilização do teste estatístico, podemos observar que BS apresentou maior quantidade de UFC; em segundo lugar, BB, e que em LB observou-se a menor quantidade de UFC (Figura 1).

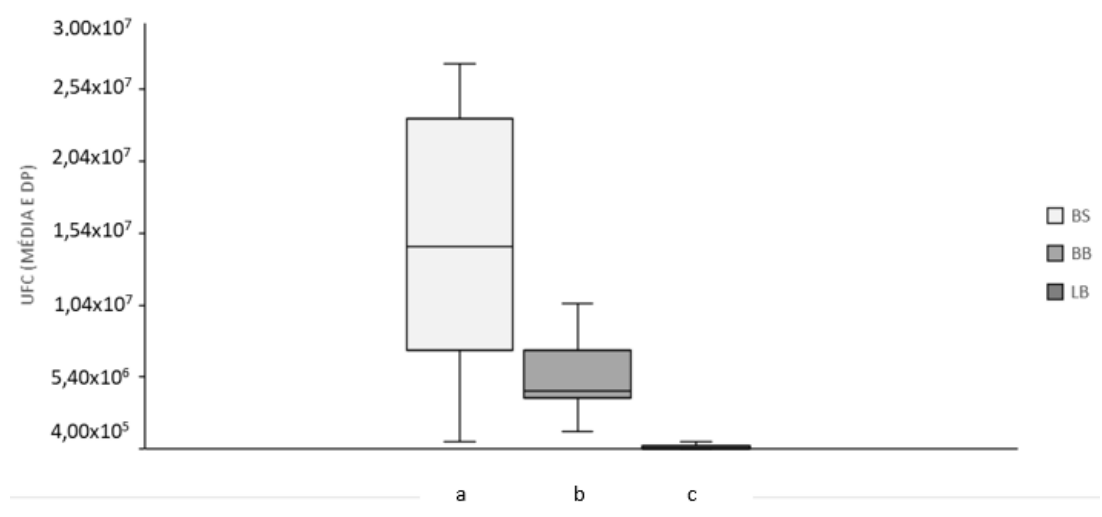

Figura 1. Box-plot para comparação dos grupos (Controle S. aureus, Bifidobacterium bifidum e Lactobacillus brevis) em relação à contagem de UFC (Unidades Formadoras de Colônia). 


\section{DISCUSSÃO}

0 tratamento utilizando bactérias probióticas visa promover a redução de microrganismos nocivos presentes em determinadas microbiotas, como, por exemplo, a do biofilme bacteriano oral.

0 mecanismo de inibição do desenvolvimento de patógenos ocorre devido à produção de ácido lático e à redução do $\mathrm{pH}$. $\mathrm{O}$ antagonismo promovido pelas bactérias láticas assume um papel importante na tecnologia de alimentos, pois está diretamente relacionado com a capacidade de produzir e tolerar uma concentração elevada de ácido lático, permitindo a inibição de outros microrganismos, favorecendo a competição com eles num ecossistema. Considerando a realidade de fabricação de queijos artesanais, sua importância socioeconômica e, sobretudo, em relação à saúde pública, crescentes avanços estão sendo feitos utilizando bactérias ácido-láticas ${ }^{14}$.

Os probióticos podem ser encontrados facilmente através de alimentos lácteos fermentados, como, por exemplo, iogurtes e queijos, além de cereais integrais e suplementação alimentar. Porém, para maior eficácia na cavidade oral, fórmulas ou dispositivos de liberação lenta podem ser necessários a fim de que os probióticos permaneçam por mais tempo na cavidade bucal. Atualmente, são comercializados probióticos em balas e chicletes ${ }^{8} .0$ uso generalizado de tais agentes é uma estratégia promissora para a manutenção e promoção da saúde humana.

Muitos estudos têm demonstrado que pacientes comprometidos periodontalmente podem ter uma experiência com uma maior perda de implantes, maior perda óssea e peri-implantite ${ }^{15}$, devido, principalmente, ao acúmulo de biofilme na região submucosa. Os estafilococos estão presentes na cavidade oral e possuem grande importância na infecção peri-implantar, já que o Staphylococcus aureus é um dos responsáveis por infecções associadas a biomateriais metálicos e infecções sistêmicas em geral. Foi demonstrado que esse microrganismo tem a capacidade de aderir a superfícies de titânio, podendo ocorrer colonização nos implantes dentários e infecções subsequentes ${ }^{16}$. Desse modo, tem-se buscado novas alternativas ao tratamento convencional das doenças peri-implantares. Sabendo-se que os probióticos competem com as bactérias que causam injúrias à saúde ${ }^{15}$, pode- se considerar que haverá uma menor colonização de estafilococos na superfície dos implantes quando esses forem utilizados como coadjuvante no tratamento da peri-implantite. A maioria das espécies bacterianas utilizadas como probióticos pertence ao gênero Lactobacillus e Bifidobacterium ${ }^{17}$.

Nesse sentido, o presente estudo avaliou a atividade antimicrobiana de cepas probióticas de Lactobacillus brevis e Bifidobacterium bifidum sobre o patógeno oral S. aureus utilizando modelo de estudo in vitro para a formação de biofilme. Os resultados do teste in vitro da atividade antibacteriana das cepas de L. brevis e B. bifidum sobre S. aureus para avaliar a interação direta entre as células desses microrganismos mostraram que houve redução significativa entre o grupo controle e os grupos teste (BS, LB e BB), contribuindo, assim, para a inibição do crescimento do biofilme bacteriano. A cepa de Lactobacillus brevis apresentou redução significativa das UFC/mL ( $\mathrm{p}<0,0001$ ), provando que possui efeito antimicrobiano sobre o $S$. aureus, reduzindo o crescimento do biofilme. A cepa de Bifidobacterium bifidum também apresentou um resultado positivo, porém o efeito potencial inibitório maior foi de L. brevis.

Um estudo realizado por Lahtinen et al. ${ }^{9}$ corroborou com os achados do presente trabalho, mostrando que três de 38 cepas de Bifidobacterium foram capazes de inibir o crescimento de S. aureus, que, mesmo presente no intestino de humanos, é uma bactéria encontrada em infecções de origem sistêmica e peri-implantares. A inibição observada por bifidobactérias foi satisfatória, porém os mecanismos pelos quais os probióticos agem em um hospedeiro não são totalmente compreendidos. Conforme descrito na literatura, supõe-se que os probióticos atuem através de vários mecanismos, incluindo: exclusão competitiva, na qual os probióticos competem com os patógenos pelos locais de fixação e nutrientes, impedindo temporariamente a ação patogênica; produção de substâncias antimicrobianas, como bacteriocinas, peróxido de hidrogênio e ácidos orgânicos voláteis; indução de alterações diretas na resposta imune, através da estimulação imune das células residentes no trato entérico, que iniciam a ativação dos macrófagos, 
aumentando a fagocitose, e modulação da atividade enzimática, alterando o metabolismo microbiano.

Lazarenko et al. ${ }^{18}$ investigaram a atividade antibacteriana de várias cepas probióticas de lactobacilos, dentre elas a cepa de Bifidobacterium bifidum contra $S$. aureus in vitro em infecção intravaginal de camundongos, e, apesar de não ter sido na cavidade bucal, os microrganismos foram os mesmos utilizados no presente estudo. Observou-se uma redução significativa no número de colônias de $S$. aureus plaqueadas da vagina dos camundongos infectados e o B. bifidum apresentou a melhor atividade antiestafilocócica, quando comparado às outras cepas probióticas de diferentes gêneros.

O estudo de Walencka et al. ${ }^{19}$, utilizando uma cepa probiótica semelhante, mostrou que os produtos derivados de Lactobacillus acidophilus podem ser utilizados como inibidores da adesão de $S$. aureus e do desenvolvimento de biofilmes, graças aos agentes ativos surfactantes produzidos pelos lactobacilos que influenciam na hidrofobicidade da superfície das células estafilocócicas.

Os lactobacilos são bactérias comensais que vivem em estreita associação com o organismo humano. A sua capacidade para inibir o crescimento de vários agentes patogênicos ganhou interesse e os lactobacilos têm sido utilizados como probióticos no intestino há décadas ${ }^{20}$. Esses microrganismos são estudados principalmente para promover efeitos benéficos sobre o trato gastrointestinal e promover a saúde humana. No entanto, a utilização de probióticos para promover a saúde bucal ainda não está bem esclarecida ${ }^{21}$. Sabe-se que a administração de probióticos concomitantemente à técnica de raspagem com o intuito de modular a composição dos biofilmes orais recém-formados tem um resultado positivo ${ }^{17,22,23}$. Apesar dos resultados propícios, ainda são necessários mais estudos sobre o uso dos probióticos na redução de patógenos presentes no biofilme bacteriano das peri-implantites.

\section{CONCLUSÃO}

Conclui-se que os probióticos analisados Lactobacillus brevis e Bifidobacterium bifidum reduziram consideravelmente o crescimento do patógeno Staphylococcus aureus. Além disso, a cepa de Lactobacillus brevis apresentou efeito inibidor superior ao da cepa de Bifidobacterium bifidum para ser utilizada como método de controle do biofilme bacteriano de Staphylococcus aureus.

\section{REFERÊNCIAS}

1. Belibasakis GN. Microbiological and immuno-pathological aspects of peri-implant diseases. Arch Oral Biol. 2014 Jan;59(1):66-72. http://dx.doi.org/10.1016/j.archoralbio.2013.09.013. PMid:24209597.

2. Gualini F, Berglundh T. Immunohistochemical characteristics of inflammatory lesions at implants. J Clin Periodontol. 2003 Jan;30(1):14-8. http://dx.doi.org/10.1034/j.1600-051X.2003.300103.x. PMid:12702106.

3. Berglundh T, Gislason O, Lekholm U, Sennerby L, Lindhe J. Histopathological observations of human periimplantitis lesions. J Clin Periodontol. 2004 May;31(5):341-7. http://dx.doi.org/10.1111/j.1600051X.2004.00486.x. PMid:15086615.

4. Mombelli A, Oosten MAC, Schürch E, Lang NP. The microbiota associated with successful or failing osseointegrated titanium implants. Oral Microbiol Immunol. 1987 Dec;2(4):145-51. http://dx.doi.org/10.1111/j.1399-302X.1987.tb00298.x. PMid:3507627.

5. Mombelli A, Décaillet F. The characteristics of biofilms in peri-implant disease. J Clin Periodontol. 2011 Mar;38(Suppl 11):203-13. http://dx.doi.org/10.1111/j.1600-051X.2010.01666.x. PMid:21323716. 
6. Persson GR, Samuelsson E, Lindahl C, Renvert S. Mechanical non-surgical treatment of peri-implantitis: a single-blinded randomized longitudinal clinical study. II. Microbiological results. J Clin Periodontol. 2010 Jun;37(6):563-73. http://dx.doi.org/10.1111/j.1600-051X.2010.01561.x. PMid:20507380.

7. Persson GR, Renvert S. Cluster of bacteria associated with peri-implantitis. Clin Implant Dent Relat Res. 2014 Dec;16(6):783-93. http://dx.doi.org/10.1111/cid.12052. PMid:23527870.

8. Bastos EM, Brito F, Da Silva RM, Fischer RG, Figueredo CMS. Probióticos na terapia periodontal. Rev Bras Odontol. 2012 Jul-Dez;69(2):224-7.

9. Lahtinen SJ, Jalonen L, Ouwehand AC, Salminen SJ. Specific Bifidobacterium strains isolated from elderly subjects inhibit growth of Staphylococcus aureus. Int J Food Microbiol. 2007 Jun;117(1):125-8. http://dx.doi.org/10.1016/j.ijfoodmicro.2007.02.023. PMid:17462772.

10. Makino LES, Peralta FS, Scherma AP, Silva CRG, Leão MVP, Santos SSF. Avaliação in vitro da influência de lactobacillus casei na aderência de enterobacter cloacae em células epiteliais da mucosa jugal. Braz J Periodontol. 2014 Dec;24(4):15-21.

11. Riccia DN, Bizzini F, Perilli MG, Polimeni A, Trinchieri V, Amicosante G, et al. Anti-inflammatory effects of Lactobacillus brevis (CD2) on periodontal disease. Oral Dis. 2007 Jul;13(4):376-85. http://dx.doi.org/10.1111/j.1601-0825.2006.01291.x. PMid:17577323.

12. Guarner F, Perdigon G, Corthier G, Salminen S, Koletzko B, Morelli L. Should youghurt cultures be considered probiotic? Br J Nutr. 2005 Jun;93(6):783-6. http://dx.doi.org/10.1079/BJN20051428. PMid:16022746.

13. Thein ZN, Seneviratne CJ, Samaranayake YH, Samaranayake LP. Community lifestyle of Candidain in mixed biofilms: a mini review. Mycoses. 2009 Nov;52(6):467-75. http://dx.doi.org/10.1111/j.14390507.2009.01719.x. PMid:19486299.

14. Chioda TP, Schocken-Iturrino RP, Garcia GR, Pigatto CP, Ribeiro CAM, Ragazzani AVF. Inibição do crescimento de Escherichia coli isolada de Queijo "Minas Frescal” por Lactobacillus acidophilus. Cienc Rural. 2007 Mar- Abr;37(2):583-5. http://dx.doi.org/10.1590/S0103-84782007000200048.

15. Sung CE, Chiang CY, Chiu HC, Shieh YS, Lin FG, Fu E. Periodontal status of tooth adjacent to implant with peri-implantitis. J Dent. 2018 Mar;70:104-9. http://dx.doi.org/10.1016/j.jdent.2018.01.004. PMid:29326047.

16. Pye AD, Lockhart DE, Dawson MP, Murray CA, Smith AJ. A review of dental implants and infection. J Hosp Infect. 2009 Jun;72(2):104-10. http://dx.doi.org/10.1016/j.jhin.2009.02.010. PMid:19329223.

17. Dias JCG, Santos CMML, Roxo MAP, Rocha LEMD, Terezan MLF. Influência clínica do uso de probióticos como adjuvantes no tratamento da periodontite crônica. Braz J Periodontol. 2018 Sep;28(3):36-45.

18. Lazarenko L, Babenko L, Sichel LS, Pidgorskyi V, Mokrozub V, Voronkova O, et al. Antagonistic action of lactobacilli and bifidobacteria in relation to Staphylococcus aureus and their influence on the immune response in cases of intravaginal staphylococcosis in mice. Probiotics Antimicrob Proteins. 2012 Jun;4(2):78-89. http://dx.doi.org/10.1007/s12602-012-9093-z. PMid:22611454.

19. Walencka E, Rózalska S, Sadowska B, Rózalska B. The influence of Lactobacillus acidophilus-derived surfactants on staphylococcal adhesion and biofilm formation. Folia Microbiol (Praha). 2008;53(1):616. http://dx.doi.org/10.1007/s12223-008-0009-y. PMid:18481220.

20. Teanpaisan R, Piwat S. Lactobacillus paracasei SD1, a novel probiotic, reduces mutans streptococci in human volunteers: a randomized placebo-controlled trial. Clin Oral Investig. 2014 Apr;18(3):857-62. http://dx.doi.org/10.1007/s00784-013-1057-5. PMid:23892501.

21. Lee SH, Kim YJ. A comparative study of the effect of probiotics on cariogenic biofilm model for preventing dental caries. Arch Microbiol. 2014 Aug;196(8):601-9. http://dx.doi.org/10.1007/s00203014-0998-7. PMid:24919536. 
22. Teughels W, Loozen G, Quirynen M. Do probiotics offer opportunities to manipulate the periodontal oral microbiota? J Clin Periodontol. 2011 Mar;38(Suppl 11):159-77. http://dx.doi.org/10.1111/j.1600051X.2010.01665.x. PMid:21323712.

23. Martin-Cabezas R, Davideau JL, Tenenbaum H, Huck O. Clinical efficacy of probiotics as an adjunctive therapy to non-surgical periodontal treatment of chronic periodontitis: a systematic review and metaanalysis. J Clin Periodontol. 2016 Jun;43(6):520-30. http://dx.doi.org/10.1111/jcpe.12545.

PMid:26970230.

\section{CONFLITOS DE INTERESSE}

Os autores declaram não haver conflitos de interesse.

\section{*AUTOR PARA CORRESPONDÊNCIA}

Mariana Cavalcante Costa Moraes, UNIT - Centro Universitário Tiradentes, Aldebaran Beta, Quadra I, Lote 24, Jardim Petrópolis, 57080-549 Maceió - AL, Brasil, e-mail: marianacostaperio@gmail.com

Recebido: Outubro 5, 2019

Aprovado: Outubro 17, 2019 